\title{
CUSTOMER PERCEPTIONS AND PURCHASE INTENTION FOR BRANDED COSMETIC PRODUCTS: AN EMPIRICAL STUDY
}

\author{
Sonam Goel* \\ Research Scholar, MMU (Ambala), Haryana, India \\ Dr Anupam Sharma \\ Associate Professor, MMU Mullana, Haryana, India \\ *Corresponding Author
}

\begin{abstract}
Customer perception for a brand plays an important role in affecting the customer purchase intention. This holds equally true for the branded Cosmetic products. This sector is becoming more and more competitive with more and more new cosmetic companies entering the market. Therefore it is essential for the companies to continuously develop their business activities in order to remain attractive to the customers. To achieve these companies need to understand the purchase intentions of the customers. The present study is to understand the customer perception and purchase intentions empirically in the context of cosmetic product. The result indicates that the perception of the customers towards a brand affects the purchase intentions. A crosssectional field study of 384 individuals was conducted to explore the factors affecting purchase intentions among consumers of NCR. Variables namely brand image, product quality, product knowledge, product involvement, product attributes and brand loyalty were studied as determinants of consumers' purchase intentions and were found to have a positive association with purchase intentions. The tests that were used in the study are common method variance, descriptive analysis $C F A$, convergent and the discriminant validity and the SEM. With all these tests the analysis was completed desired results were achieved.
\end{abstract}

Key words: Branded Cosmetic Products, product quality, Trust, product attributes, brand loyalty, purchase intentions.

Cite this Article: Sonam Goel and Anupam Sharma, Customer Perceptions and Purchase Intention for Branded Cosmetic Products: An Empirical Study, International Journal of Management, 11(12), 2020, pp. 1997-2009.

http://iaeme.com/Home/issue/IJM?Volume=11\&Issue=12 


\section{INTRODUCTION}

Purchase intention is the willingness to purchase a product which may be first time or repeat purchase (Fandos \& Flavian, 2006; Halim \& Hameed, 2005). It is important because the companies want to generate revenue by increasing the market share to maximize their profit. Purchase intention is an indication towards customer retention. Functions such as product knowledge, product involvement, product attributes and Brand strength have a strong influence on the purchase intention. The present study reveals the important factors that have significant effect on the purchase intention of the customers. From the marketing perspective it is important to understand the customer needs and wants from the product. This understanding helps the marketers to focus on those needs that are significant with purchase intentions of the customers. The customer centric approach helps to find out the preferences and perception of users. The branded products have features that create a distinct image and positive perception in the mind of the customers. These features about the brands affect the perception of customers (Teoh et al., 2013). The consumer's behaviour is mostly determined by the perceptions and attitudes which determine the purchase intentions. The success of a brand or a cosmetic product depends on the purchase behaviour of the consumers. Consumer buying behaviour which is defined as the analysis of when, where, why, and how consumers purchase a product, focuses on understanding the needs, wants of the consumer for products success. It helps in determining the purchase intention that can predict future trends. Previously the consumer's perception towards the cosmetic products was negative because the consumers perceived that these products contain a harmful chemicals which can harm the skin but now this perception have changed with time. Present generations are very conscious about their looks and therefore depend on the branded cosmetic products for improving their appearance.

\subsection{Cosmetic products}

The cosmetic products are used to enhance the appearance of human beings. After 1991 due to liberalization 1990s coupled with the crowning of Indian women in beauty contests led to the increase in the demand for the branded cosmetic products. In the present scenario the Indian cosmetic industry has a tremendous potential due to growing consumers interest in their looks and interest in herbal cosmetic products especially with the launch of Patanjali products. The top leading Indian cosmetic companies are Lakme, Revlon, Oriflame Cosmetics, Biotique, Himalaya Herbals, and VLCC etc. The history of cosmetics spans at least 6,000 years and almost every society used cosmetic products in one way or the other. The tattoos and scarification practised by many people are all forms of cosmetic used for intimidating the enemy psychologically (Draelos, 2007). The FDA USA defines cosmetics as products "intended to be applied to the human body for cleansing, beautifying, promoting attractiveness, or altering the appearance without affecting the body's structure or functions." The FDA specifically excludes soap from this particular category. The oldest and the largest cosmetic company is L'Oreal, founded by Eugene Schueller in 1909 as the French Hair Coloring Company. These firms were joined by Revlon before World War II (Mayell, 2004). According to Whittaker (2007), there are approximately 3,300 cosmetic companies related to cosmetic and skincare products in the United States alone and it is growing continuously. The beauty products can be herbal or chemically laden, the demand for herbal products have also increased substantially due to many upcoming brands by male or female. The cosmetic products contain chemicals in traditional cosmetics can cause harm to the skin of the consumers (Seinfeld and Pandis, 2016; Andrady, 2011). Over the last few years, consumers have become aware of the herbal products and have developed a liking for these cosmetic products for a healthy lifestyle. The consumers are aware of the negative impact of harmful chemically laden cosmetics (Chery and Wischhover, 2018). The impact on the environment due to purchase decisions is also considered by some customers. 
The herbal cosmetics not only meet consumers' needs but also promote the development of the cosmetics industry in a more sustainable way (Matić and Puh, 2016).

\subsection{Perceptions and Purchase Intentions}

The positive perception of the customer towards products determines the purchase intentions of the consumers. These terms are related to the consumer behaviour and are difficult to understand for most of the companies. The perception of the customer can be positively changed by continuously offering better products which delights the customer. The brand image and consistent product quality also contributes in the perception process. For example with some cases of harmful consequences of using chemical laden cosmetic products the customers have started showing interest and liking towards herbal cosmetic products because of increased health consciousness. Due to these changes in the purchase intentions the companies need to focus $n$ these areas to increase the market share. Noel (2009) contended that before the perception process starts the exposure to a product or service is essential. From the perspective of consumer behaviour, the perceptions affect a consumer's purchase intentions and therefore it is an important area for the marketers. The purchase intention of the consumer is influenced by his or her perception towards a product or service. Different consumers have different perceptions for the same product. The whole process of perception starts with the sense organs by picking up a stimulus in the form of a product or service. The three senses of vision, smell and touch are relevant. The stimulus is picked up by sensory receptors and attention is generated which leads to an interpretation of the information. This interpretation of the information depends on the personal factors and personality traits of the consumer. The Perceptions are formed in the mind of the customer through a three-stage process which is called selective attention, selective distortion and selective retention. Kotler and Keller (2009) defined attention as the mind's processing capacity to some stimulus. The consumer selects the stimuli as per its mind's capacity. This selective stimulus is called selective attention. The consumers pay attention to those stimuli which relate to the needs of the customers. This entire process can be diagrammatically represented as follows which is given by Solomon et al. (2006).

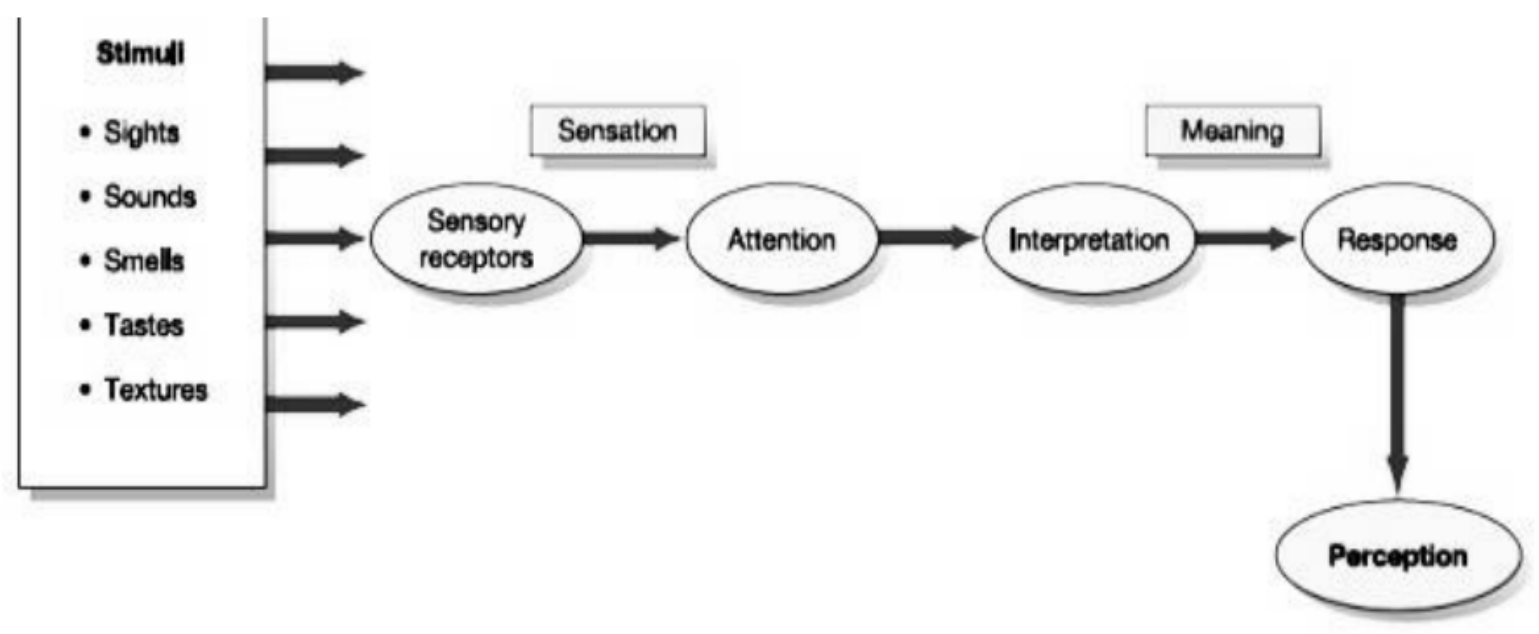

Figure 1 An overview of the perceptual process; (Solomon et al. 2006)

\subsection{Significance of the study}

The beauty industry is a fast growing industry with the usage of cosmetic products by young generation for better looks and personal appearance. The study focuses on identifying the factors and understanding the behavioural intentions and customer perception of the consumers with respect to branded cosmetic products. The sample area of study is NCR because it's a 
metropolitan area and most of the working professional uses the cosmetic products. The study targets both male and the females in the study between the age group of 16-40 years. The sample size of the study would be approximately 384 customers. This study will contribute to a better understanding of the factors impacting the consumer buying behaviour. The recommendations given at the end would help the marketers to formulate the marketing strategies related to consumer behaviour more effectively. This study will help the marketers with empirical evidence based on the knowledge of marketing practitioners and academicians regarding the different variables used in this study. The study will increase the understanding of the concept of "brand" in a market full of unbranded FMCG products. In Indian markets where marketing is mostly organizational oriented, using customer driven approach will help the marketers in gaining insight about consumer's perception for effective outcome.

\section{LITERATURE REVIEW}

Halim and Hameed (2005) described purchase intention as a process in which the consumers buy the products and make repetition purchases for the specific product. Kang et.al, (2011) explains the four behaviors of consumers related to purchase intention including the undoubted plan for product purchase, thinking to purchase the product, contemplating to buy the product in the future, and to purchase the specific product. Fandos and Flavian (2006) contented that the purchase intention is a projected behavior of consumers about the repetition purchase of specific product i.e. it is a willingness to one's self to purchase the product. Purchase intention is a multi-step process in which first of all the consumer collect the information about the brand then evaluate its attributes to suits with the buyers intentions then they decide to make a purchase, when the consumer finally purchases the product the consumer gains personal experience, if the consumer is satisfied with the brand then they will show interest to purchase the brand again, this process is called as "purchase intention". This behavior of purchase of a specific product is called purchasing behavior. Some independent variables such as brand image, product quality, product knowledge, product reviews, product features, positively impacts the purchase intentions. Arslan and Altuna (2010) defines brand image as the positive and negative feeling about the brand and it is also about the recall of the product while making the purchase. The study further elaborates the three aspects of brand image which make which are; favorability, strength, and distinctiveness. Another study by Meenaghan (1995) defines brand image with respect to the attitudes of the consumers which helps in the significant way to make the product purchase. Bian and Moutinho (2011) states brand image as the set of statements for the target market to capture their purchase intentions. Lee and $\mathrm{Wu}$ (2011) highlighted brand image in their study as the overall beliefs about the brand by keeping in mind its unique features. Thus it can be concluded that the brand image is an important variable which affects the purchase intentions of the consumers. It motivates the consumers to go for a specific brand having good brand image forcing them to make purchase intentions. The Product attributes, brand personality, and brand benefits defines the image of the brand. Higher the brand image more will be the purchase intention for the specific brand. Wu \& Wu, in their study collected data from the respondents between 18 to 40 years in three countries like Taiwan, Japan and Europe, after the data analysis it was empirically concluded that each dimension of brand image has a positive effect on the purchase intention. Chi, Yeh and Huang (2008) study also focussed on the influence of brand image on consumer purchase intention. Lin et.al. (n.d) showed the relationship between brand image and purchase intention and concluded that the brand image has a significant positive relationship with the consumers' purchase intention. Eze, Tan, Yeo (2012) also found and proved that there is positive relationship between brand image and consumer purchase intention. So based on above studies we can develop our hypothesis as:

H1: Brand image has a significant and positive relationship with purchase intentions. 
Prieto, Revilla and Prado (2009) contended that product knowledge is the accumulation of experiences which we gain over time. Product knowledge also includes the information about the company and their processes which are undertaken in producing a product. $\mathrm{Fu}$, Chui \& Helander (2006) explained product knowledge in their study as the ideas that give direction towards purchasing a product. This accumulated information is filtered by the consumers mind, based on which it makes a decision about the product purchase. Bian and Moutinho (2011) in their study explained how product features and the source of information for gaining product knowledge persuades all the process of the consumer decision making. The source of information and product knowledge varies from consumer to consumer due to usage of different sources and also due to different level of sensitivity of the consumers mind. The focus of the study was on source credibility which leads to product knowledge and finally leads to purchase intention which impacts the purchase behavior of the consumers. Thus the product knowledge is the descriptive understanding of the product and its features which consumers wants to get from credible and reliable sources for making informed purchase decisions. For example if a consumer goes to the market he will prefer those products about which it has credible information. Therefore companies try to provide relevant and credible information to the consumers to enhance their product knowledge by using different online and offline platforms for the consumers. The credibility and reliability of the product information leads to trust building which increases the customer loyalty for the product or service. So it can be concluded that if the consumers have more product knowledge then they would be able to make more informed choices and in this process the credibility of the source plays a pivotal role. Lin, Yeh, Chung, Wen, (n.d) study confirmed that the product knowledge has a significant positive relationship with the consumer purchase intention. Pedersen \& Nysveen (2005) study emphasizes on the same point. Eze, Tan, Yeo (n.d) studied product knowledge to find out its effect on the consumer purchase intention. The study found a positive relationship between product knowledge and consumer purchase intention. This leads to another hypothesis as:

$\mathrm{H} 2$ : Perceived source trustworthiness has a significant and positive relationship with purchase intentions.

Wickliffe and Pysarchik (2001) explained product attributes as those features which have strong influence on the consumer purchase behaviour. The brand attributes may include the brand name, the price of the product, uniqueness, look, colour, weight, quality etc. Out of these attributes Brand name and price are the important attributes of the product. Abbott et al, (2009) in their study defined product attributes as the sensory processes of the product which includes the design, technology, engineering processes of the product which contributes to the overall attractiveness of the product and impacts the consumer purchase intentions. So it highlights that product attributes helps in positioning of the product, the product attributes can be weak or strong but the consumer satisfaction is heavily dependent on the product attributes. Bian and Another study by Moutinho (2011) explained product attributes as the expressive features that provides uniqueness to the product and distinguish the product from the competitors. The product attributes can be Intrinsic or extrinsic. Intrinsic attributes are those which influence the product directly and extrinsic are those which indirectly influence the product. Attributes of the product conveys the company's image and philosophy to the consumers. They are the features which gives a product uniqueness and inviduality in the market. The product attributes differs from product to product and provides brand equity to the company. The consumer Satisfaction is dependent on the product attributes. If the consumers are satisfied they would make repeat purchases and will spread positive word of mouth for the brand. Bianand Moutinho (2011) studied focussed on how and in what way product attributes influences the customer purchase behavior. Their study concluded that the product attributes are the significant predictor of purchase intention. Jung \& Bonn (2005) also emphasized that there is a significant effect of 
product attributes on consumer purchase intention. On the basis of literature another formulated hypothesis is as follows:

H3: Product attributes has a significant and positive relationship with purchase intentions.

With the penetration of internet in the remotest areas the customer have now started using this medium to interact with one another and this communication over online platforms is known as electronic word of mouth. It is the fastest and easiest communication methods to spread god things about the product. Christy M.K. Cheung et al (2008), in their study highlighted the importance of Web technologies and how they play a crucial role in electronic word of mouth. The marketers have starting exploiting these opportunities to promote their products and services along with electronic WOM communication through online platforms. Individual opinions are considered as trustworthy before making buying decision. Kala and Chaubey (2018), found in their study on electronic word of mouth that the marketer should use eWOM as a means to increase brand popularity which further impacts the consumer purchase intention. The authors concluded that brand image act as mediator between eWOM and purchase intention. The reliability and credibility of eWOM communication has huge effect on consumer purchase behavior. People trust the user's recommendation to make a product choice leading to affirmative purchase intention. Francesca Di Virgilio and Gilda Antonelli (2017) found that online platforms help the consumers to create and exchange user-generated content. The study focused on the mediating role of eWOM and trust on the consumers purchase intention. The study concluded by emphasizing on the product familiarity and product related information shared on various online platforms. The study concluded that eWOM communication and trust have impact on purchase Intention. Mayank Sharma et al (2015), in their study concluded that social online groups have grown rapidly and these groups allow the user to exchange the eWOM information with peer to peer communities. These online communities strengthen the trust among user and therefore positively influence the purchase decision of products and services through electronic word of mouth. Noraini Sa'ait et.al (2016), conducted their study to find the influence of positive eWOM on purchase intention. The study found that eWOM element like accuracy, comprehensiveness; relevance and timeliness have significant relationship with customer purchase intention. The eWOM information is a source for honest reviews by prior purchaser. The eWOM receiver who received prior purchaser information will have purchase intention after reviewing various reviews. T. Wang et al (2016), found in their study that eWOM influence the purchase decision of consumer. Consumer shares product related information and the prospective consumer trust the information posted by previous used for making purchase decisions.

H4: Positive Electronic Word of Mouth has a significant and positive relationship with purchase intentions.

These dimensions may be summarized in the following model.

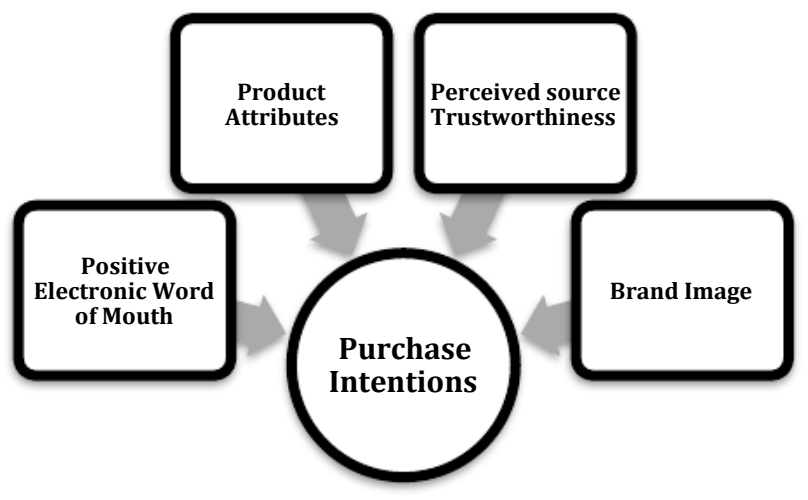

Figure 2 


\section{OBJECTIVES \& HYPOTHESIS}

The objectives on which the study is based are as follows:

- To study the perception of consumer's towards eWOM.

- To measure the impact of eWOM on purchase intentions.

The hypotheses formulated are as follows:

H1: Perceived source expertise has a significant and positive relationship with purchase intentions.

H2: Perceived source trustworthiness has a significant and positive relationship with purchase intentions.

H3: Product attributes has a significant and positive relationship with purchase intentions.

H4: Positive Electronic Word of Mouth has a significant and positive relationship with purchase intentions.

\section{METHODOLOGY}

The study carried extensive literature review to develop the conceptual framework. The study through the literature review identified some relevant independent and dependent variables. The identified independent and dependent variables were utilised in the study. This paper followed the mix pattern of research design i.e. exploratory and quantitative approach towards the multiple causal relationship measurement. The sample size was arrived at by assuming the total number of population at $100000000 \ldots \mathrm{n}^{\text {th }}$ and the confidence interval is taken as $95 \%$, which arrives at the figure of 384 as the sample size.

The total constructs used in the study, both independent and dependent are as follows:

Table 1

Constructs identified through Literature Review

1. Source trustworthiness

2. Receiver expertise

3. Valence of eWOM

4. Type of Website

5. Nature of Product

6. Customer purchase Intensions

7. Perceptions

8. Trust and Truth tendencies

9. Satisfaction

Source: Literature reviews

\subsection{Analysis and Results:}

The study used the methodological framework in terms of tools for statistics to be used for objective fulfillment. The main tools used for analysis in the study are descriptive analysis, reliability analysis by using the Cronbach's alpha, Harman test of common method bias to measure the biasness in the study, measurement model for eWOM (Confirmatory factor analysis), analysis of mean and standard deviation were also used followed by structural equation model (structural model) and finally the path direction method was used to measure the standardized regression weight which helped in drawing inferences from the data collected from the targeted population. 
Table 2

\begin{tabular}{|c|c|c|}
\hline \multicolumn{3}{|c|}{ Demographic profile $(\mathrm{N}=384)$} \\
\hline $\begin{array}{l}\text { Elements of demographic } \\
\text { profile }\end{array}$ & $\begin{array}{l}\text { Indicators of element of } \\
\text { Demographic profile }\end{array}$ & Frequencies \\
\hline Gender & $\begin{array}{l}\text { Male } \\
\text { Female }\end{array}$ & $\begin{array}{l}278 \\
106\end{array}$ \\
\hline Age & $\begin{array}{l}15-20 \\
20-25 \\
25-30 \\
30-35 \\
\end{array}$ & $\begin{array}{c}65 \\
159 \\
140 \\
20 \\
\end{array}$ \\
\hline Educational Qualifications & $\begin{array}{l}\text { Under-graduate } \\
\text { Graduate } \\
\text { Post-graduate } \\
\text { Doctoral }\end{array}$ & $\begin{array}{c}124 \\
100 \\
99 \\
61\end{array}$ \\
\hline Marital Status & $\begin{array}{l}\text { Married } \\
\text { Unmarried }\end{array}$ & $\begin{array}{l}144 \\
240\end{array}$ \\
\hline Occupation & $\begin{array}{c}\text { Govt Job } \\
\text { Own Business } \\
\text { Student } \\
\text { Private Job }\end{array}$ & $\begin{array}{c}75 \\
19 \\
180 \\
110 \\
\end{array}$ \\
\hline Monthly Income & $\begin{array}{c}15000-25000 \\
25000-35000 \\
35000-45000 \\
45000-55000 \\
\text { More than } 55000\end{array}$ & $\begin{array}{c}90 \\
101 \\
98 \\
60 \\
35\end{array}$ \\
\hline
\end{tabular}

Source: Primary Data

The analysis of the data using relevant tools indicated that the perception plays an important role in shaping consumers' attitudes and purchase intentions toward the product or service and it ultimately increase eWOM effectiveness. The measurement of perceptions provided the information that the consumers are having relatively stronger eWOM as shown in the mean score in the table 2. (PER_1 to PER_5) was measured by using the descriptive statistics. The perceptions of consumers about the product design along with the review is also an important aspect for the consumers in electronic word of mouth as indicated in the PER 1 (Mean+ S.D. $=3.6833+1.09562)$. This means that the customer not only see the review online but along with that the consumers also see the product design in the preference of the product.

Table 3

\begin{tabular}{|l|c|c|c|c|c|}
\hline \multicolumn{7}{|c|}{ Perception of consumer's towards eWOM } \\
\hline & $\mathrm{N}$ & Minimum & Maximum & Mean & Std. Deviation \\
\hline PER_1 & 384 & 1.00 & 5.00 & 3.6833 & 1.09562 \\
\hline PER_2 & 384 & 1.00 & 5.00 & 3.3467 & 1.09719 \\
\hline PER_3 & 384 & 1.00 & 5.00 & 3.2900 & 1.13292 \\
\hline PER_4 & 384 & 1.00 & 5.00 & 3.2667 & 1.05162 \\
\hline PER_5 & 384 & 1.00 & 5.00 & 3.4500 & 1.19398 \\
\hline Source: Primary Data
\end{tabular}


The price of the product price is also the important factor along with the electronic reviews of the consumers on e-tailing website or any other platform as indicated in the PER_2 (Mean + S.D. $=3.3467+1.09719)$ dimension of the perception. The online review is not only the deciding factor, but the price plays an important role in decision of the consumers to prefer the cosmetic product. The third aspect of the research instrument in terms of perception of the consumers toward the eWOM is coded as PER_3 (Mean + S.D. $=3.2900+1.13292)$ which indicated that if there is any case of the high rating then sometimes the electronic word of mouth becomes secondary in product purchase decisions. Further, the PER 4 and PER_5 are another dimensions of the perception of consumers toward the eWOM with the results of Mean and standard deviation as (Mean + S.D. $=3.2667+1.05162)$ which depicts towards the direction of something meaningless about the negative review by the consumers, if the products has been often used by the consumers.

In the total number of observed variables it was found that the source expertise is explaining the variance of $14.3 \%$ with significant $p$ - value of 0.015 , the source trustworthiness is indicating the standardized regression weight of $1.1 . \%$ with the insignificant $p$-value of 0.811 ,receiver expertise ( -0.009 and 0.856$)$, valence of eWOM (.450 and the $p$ value is indicated as triple star as $* * *$ which indicates that the valence of eWOM is explaining the variance of 45 $\%$ at the $99 \%$ of confidence interval), types of website (Standardized regression weight is .076 and the $p$-value 2.54), nature of product (Standardized regression weight 0.405 , in essence it explaining the variance of the $40.5 \%$ and $p$-value 0.14).The structural equation model indicates the impact of eWOM on purchase intentions.

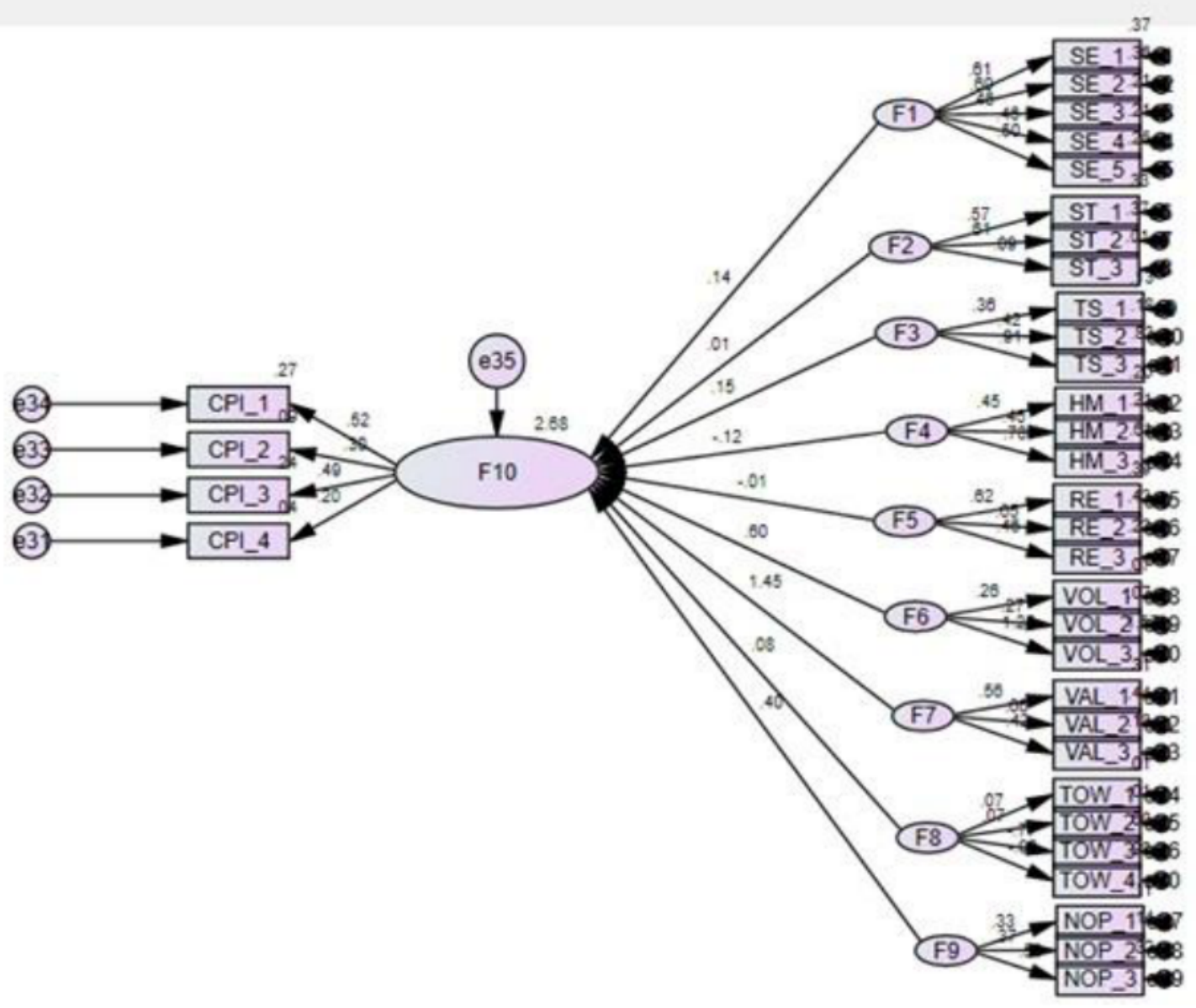

Figure 3 Impact of eWOM on purchase intentions

Source: Primary Data 
All the mean and standard deviation are indicative of the fact that all the observed variables are explaining the relative degree of agreement to the questions asked. The observed variable indicated the mean and standard deviation as (3.36331 and .15576 respectively) and it means that the "previous reviews on the website affects the willingness of the consumers to make a decision to buy or not".

The analysis was conducted on the basis of the data collected from the 384 respondents. The data was analyzed in two different groups as preliminary and the objective wise analysis. The total tests that were used are - common method variance, descriptive analysis CFA, convergent and the discriminant validity and the SEM. With all these tests the study analysis was completed and arrived at desired results.

\section{FINDINGS \& DISCUSSION}

The study focussed on the key constructs of the eWOM, which are purchase intentions, perceptions, actual purchase and satisfaction. The eWOM concept is having 9 variables theoretically categorized as given below -

- Source trustworthiness

- Receiver expertise

- Valence of eWOM

- Type of Website

- Nature of Product

- Customer purchase Intensions

- Perceptions

- Trust and Truth tendencies

- Satisfaction

The electronic word of mouth also called eWOM is a concept based on people's reviews, rating and recommendations based on the experiences of their purchase. The eWOM variables and the related aspects were adapted for the measurement of the cause and effect relationship. On the basis of the literature reviews the study arrived at the conceptual framework. The questionnaire was devised on the basis of existing scale and further the created scale, in essence, there are combination of own questions and the modified questions based on the existing studies and the thought of the researchers. The questionnaire had questions related to demographic information wherein there were demographic questions particularly on seven elements such asGender, Marital Status, Education level, Occupation, Household Income, and Age and moreover, the elements of eWOM was undertaken as the independent variable to measure the cause and effect relationships. The dependent variable was undertaken on the basis of the literature reviews as the concept of customer purchase Intensions. Initially, the analysis was stated by using the common method variance is accordance with the Harman's method was analyzed and the finding of the study suggested that based on the common method variance biasness does exist but within the acceptable range. The Common Minimum Variance analysis states that, if the variance explained in less than $50 \%$ then the study is just can carried forward for the purpose of the study.

\section{CONCLUSION}

The study in the present paper was conducted with the common method bias where the biasness check was the main aim in order to avoid any type I and II error. So, these errors were initially done away with to go for further analysis, the other way of the data analysis is in the objective wise category. After this the data was analyzed with the demographic variables taken from the 
sample size by using street intercept method. For the research instrument preparation extra caution was undertaken at the initial stage.

The main highlights of the study are given below as follows-

- The objective wise analysis was carried through the descriptive research and initially the mean and the standard deviation was used as the base in taking the inferences from the sample taken from the population in the form of customer's responses.

- The other aspect is the cause and effect relationship of eWOM with the purchase intention, the study incorporated is confirmatory factor analysis where in the individual items was checked by using the individual factor loadings and on the basis of the individual factor loading the construct reliability spread into convergent and the discriminant validity was checked and inferences of the validity of the observed and the latent variables was extracted.

- The other aspect is of measuring the cause and effect relationship with the stimuli and the responses. The SEM model was created using AMOS 22 version, and initially the model fit was measured and then the path diagram was analyzed and inferences were drawn on the basis of the standardised regression weight and the classification were given in addition to hypotheses decision of accepted or not accepted .

- Lastly the perception, actual purchase, were analyzed by using the descriptive statistics specifically using the mean and the standard deviation arising from the mean and broadly from the responses from the consumers' responses, and the inferences were drawn and put to the implication to the marketing theory and the practice in terms of the resultant output.

\section{SUGGESTION FOR FUTURE RESEARCH}

The present study does not provide the ending output; and this process in on and on by several researchers to provide new ways to the existing study field and the literature. Some of the recommendations for the future research are given as the future researchers is required to further make extension of research and address the restrictions based on area specific and further the compositions and the cultural aspects, i.e. the cultural settings. Further research is also recommended by taking into consideration the likeability of the cosmetic products spread across the genders and different age groups.

\section{IMPLICATIONS OF THE STUDY}

The implication of the current study is that it provides the academic knowledge about the concept of eWOM with the drawn-out primary research in area of eWOM. This study will assist the academic research and the marketer. The academic research can be taken as a reference for the research design and the instrument especially, the constructs of the study. The marketing manager can take can take reference from the electronic word of mouth impact on the purchase intentions and act accordingly.

\section{REFERENCES}

[1] Fandos, C., \& Flavian, C. (2006). Intrinsic and extrinsic quality attributes loyalty and buying intention: an analysis for a PDO product. British food journal.

[2] Halim, W.Z.W. \& Hamed, A.B. (2005). Consumer purchase Intention at traditional restaurant and fast food restaurant. Paper presented at ANZMAC 2005 Conference: Consumer Behavior 
[3] Teoh, W. M. Y., Chong, S. C., Lin, B., \& Chua, J. W. (2013). Factors affecting consumers' perception of electronic payment: an empirical analysis. Internet Research.

[4] Draelos, Z. D. (2007). Skin lightening preparations and the hydroquinone controversy. Dermatologic Therapy, 20(5), 308-313.

[5] Mayell, H. (2004). As consumerism spreads, Earth suffers, study says. National Geographic News, 12.

[6] Whittaker, K. (2007). [Online] Available: http://cosmeticsuniverse.com/.

[7] Seinfeld, J. H., \& Pandis, S. N. (2016). Atmospheric chemistry and physics: from air pollution to climate change. John Wiley \& Sons.

[8] Andrady, A. L. (2011). Microplastics in the marine environment. Marine pollution bulletin, 62(8), 1596-1605.

[9] Chery, Wischhover, 2018, Available at: https://www.vox.com/thegoods/2018/9/18/17866150/natural-clean-beauty-products-f einstein-cosmetics-bill-fda.

[10] Matić, M., \& Puh, B. (2016). CONSUMERS'PURCHASE INTENTIONS TOWARDS NATURAL COSMETICS. Ekonomski vjesnik/Econviews-Review of Contemporary Business, Entrepreneurship and Economic Issues, 29(1), 53-64.

[11] Noel, H. (2009). Basics marketing 01: Consumer behaviour (Vol. 1). Ava Publishing.

[12] Solomon, M., Bamossy, G., Askegaard, S. \& Hogg M. K. (2006). Consumer Behaviour; A European Perspective, Prentice Hall-Financial Times, London, Third Edition, p. 36-38.

[13] Kang, J., Liu, C., \& Kim, S. H. (2013). Environmentally sustainable textile and apparel consumption: the role of consumer knowledge, perceived consumer effectiveness and perceived personal relevance. International Journal of consumer studies, 37(4), 442-452.

[14] Fandos, C., \& Flavian, C. (2006). Intrinsic and extrinsic quality attributes loyalty and buying intention: an analysis for a PDO product. British food journal.

[15] Arslan, F. M., \& Altuna, O. K. (2010). The effect of brand extensions on product brand image. Journal of Product \& Brand Management.

[16] Meenaghan, T. (1995). The role of advertising in brand image development. Journal of product \& brand management.

[17] Bian, X., \& Moutinho, L. (2011). The role of brand image, product involvement, and knowledge in explaining consumer purchase behaviour of counterfeits. European Journal of Marketing.

[18] Lee, H. M., Lee, C. C., \& Wu, C. C. (2011). Brand image strategy affects brand equity after M\&A. European journal of marketing.

[19] Chi, H. K., Yeh, H. R., \& Huang, M. W. (2008). The Influences of Advertising Endorser, Brand Image, Brand Equity, Price Promotion, on Purchase Intention. The Mediating Effect of Advertising Endorser, Retrieved December, 5, 2011.

[20] Eze, U. C., Tan, C. B., \& Yeo, A. L. Y. (2012). Purchasing cosmetic products: A preliminary perspective of Gen-Y. Contemporary management research, 8(1). 
[21] Prieto, I. M., Revilla, E., \& Rodriguez-Prado, B. (2009). Building dynamic capabilities in product development: How do contextual antecedents matter?. Scandinavian Journal of Management, 25(3), 313-326.

[22] Fu, Q. Y., Chui, Y. P., \& Helander, M. G. (2006). Knowledge identification and management in product design. Journal of Knowledge Management.

[23] Bian, X., \& Moutinho, L. (2011). The role of brand image, product involvement, and knowledge in explaining consumer purchase behaviour of counterfeits. European Journal of Marketing.

[24] Nysveen, H., Pedersen, P. E., \& Thorbjørnsen, H. (2005). Intentions to use mobile services: Antecedents and cross-service comparisons. Journal of the academy of marketing science, 33(3), 330-346.

[25] Wickliffe, V. P., \& Pysarchik, D. T. (2001). A look at product attributes as enhancers of group integration among US and Korean consumers. International Journal of Retail \& Distribution Management.

[26] Abbott, M., Holland, R., Giacomin, J., \& Shackleton, J. (2009). Changing affective content in brand and product attributes. Journal of Product \& Brand Management.

[27] Jang, Y. J., Kim, W. G., \& Bonn, M. A. (2011). Generation Y consumers' selection attributes and behavioral intentions concerning green restaurants. International Journal of Hospitality Management, 30(4), 803-811.

[28] Cheung, C. M., Lee, M. K., \& Rabjohn, N. (2008). The impact of electronic word-of-mouth: The adoption of online opinions in online customer communities. Internet Research: Electronic Networking Applications and Policy, 18(3), 229-247.

[29] Kala, D., \& Chaubey, D. S. (2018). The effect of eWOM communication on brand image and purchase intention towards lifestyle products in India. International Journal of Services, Economics and Management, 9(2), 143-157.

[30] DI VIRGILIO, F., \& Antonelli, G. (2017). Consumer behavior, trust and electronic word-ofmouth communication: toward a model of understanding of consumer's purchase intentions online.

[31] Sharma, M., Kumar, P. and Bhasker, B. (2015)_Purchase intention and word of mouth in social apps', Int. J. Web Based Communities, Vol. 11, No. 2, pp.188-209.

[32] Sa'ait, N., Kanyan, A., \& Nazrin, M. F. (2016). The effect of e-WOM on customer purchase intention. International Academic Research Journal of Social Science, 2(1), 73-80. 